\title{
Dynamics of hydration water in deuterated purple membranes explored by neutron scattering
}

\author{
K. Wood · M. Plazanet $\cdot$ F. Gabel $\cdot$ B. Kessler • \\ D. Oesterhelt $\cdot$ G. Zaccai $\cdot$ M. Weik
}

Received: 12 October 2007/Revised: 22 January 2008/Accepted: 31 January 2008/Published online: 20 February 2008

(c) EBSA 2008

\begin{abstract}
The function and dynamics of proteins depend on their direct environment, and much evidence has pointed to a strong coupling between water and protein motions. Recently however, neutron scattering measurements on deuterated and natural-abundance purple membrane (PM), hydrated in $\mathrm{H}_{2} \mathrm{O}$ and $\mathrm{D}_{2} \mathrm{O}$, respectively, revealed that membrane and water motions on the ns-ps time scale are not directly coupled below $260 \mathrm{~K}$ (Wood et al. in Proc Natl Acad Sci USA 104:18049-18054, 2007). In the initial study, samples with a high level of hydration were measured. Here, we have measured the dynamics of PM and water separately,
\end{abstract}

Advanced neutron scattering and complementary techniques to study biological systems. Contributions from the meetings, "Neutrons in Biology", STFC Rutherford Appleton Laboratory, Didcot, UK, 11-13 July and "Proteins At Work 2007", Perugia, Italy, 28-30 May 2007.

K. Wood · F. Gabel · G. Zaccai · M. Weik ( $)$

Laboratoire de Biophysique Moléculaire, Institut de Biologie Structurale CEA-CNRS-UJF,

41 rue Jules Horowitz, 38027 Grenoble Cedex 1, France

e-mail: weik@ibs.fr

K. Wood · G. Zaccai

Institut Laue-Langevin, 6 rue Jules Horowitz, B.P. 156,

38042 Grenoble Cedex 9, France

K. Wood · B. Kessler $\cdot$ D. Oesterhelt

Max-Planck Institut für Biochemie, 82152 Martinsried, Germany

Present Address:

K. Wood

Biophysical Chemistry, University of Groningen, Nijenborgh 4,

9747 AG Groningen, The Netherlands

\section{Plazanet}

European Laboratory for Non-Linear Spectroscopy,

University of Florence, Via Nello Carrara 1,

50019 Sesto-Fiorentino, Italy at a low-hydration level corresponding to the first layer of hydration water only. As in the case of the higher hydration samples previously studied, the dynamics of PM and water display different temperature dependencies, with a transition in the hydration water at $200 \mathrm{~K}$ not triggering a transition in the membrane at the same temperature. Furthermore, neutron diffraction experiments were carried out to monitor the lamellar spacing of a flash-cooled deuterated PM stack hydrated in $\mathrm{H}_{2} \mathrm{O}$ as a function of temperature. At $200 \mathrm{~K}$, a sudden decrease in lamellar spacing indicated the onset of long-range translational water diffusion in the second hydration layer as has already been observed on flash-cooled natural-abundance $\mathrm{PM}$ stacks hydrated in $\mathrm{D}_{2} \mathrm{O}$ (Weik et al. in J Mol Biol 275:632-634, 2005), excluding thus a notable isotope effect. Our results reinforce the notion that membrane-protein dynamics may be less strongly coupled to hydration water motions than the dynamics of soluble proteins.

Keywords Neutron spectroscopy $\cdot$ Hydration water dynamics · Purple membrane - Dynamical transition
Abbreviations
BR Bacteriorhodopsin
PM Purple membrane
EINS Elastic incoherent neutron scattering
MD Molecular dynamics
MSD Mean square displacements

\section{Introduction}

The purple membrane (PM) has provided biophysicists with an exceptional model of study. Natively forming a 
two-dimensional crystal, PM contains a unique protein, viz. the light-driven proton pump bacteriorhodopsin (BR), and various lipid species. From the external membrane of Halobacterium salinarum, PM can be purified relatively easily in large quantities necessary for neutron scattering measurements. PM dynamics has been well-characterised by neutron scattering at various time and space scales for different hydration levels (Ferrand et al. 1993; Fitter et al. 1996, 1997; Lehnert et al. 1998) and different lipid contents (Fitter et al. 1998). Isotope labelling of the membrane has been successfully performed (Engelman and Zaccai 1980; Patzelt et al. 1997), and combined with incoherent neutron scattering experiments, revealed the dynamical heterogeneity of PM on the ps-ns time scale, with the core of BR found to be stiffer than its surroundings (Reat et al. 1998).

Hydrated PM undergoes a so-called dynamical transition at around $230-260 \mathrm{~K}$, evidenced in incoherent neutron scattering experiments as a sudden increase in the atomic mean square displacement (MSD) as a function of temperature (Ferrand et al. 1993; Fitter et al. 1997; Lehnert et al. 1998). Neutron scattering experiments on soluble proteins (Doster et al. 1989; Fitter 1999; Roh et al. 2006; Wood et al. 2008), on another membrane protein (Pieper et al. 2007) and on RNA (Caliskan et al. 2006) revealed the same phenomenon at a temperature between 180 and $250 \mathrm{~K}$.

The dynamical transition only occurs in sufficiently hydrated systems, and changing the solvent composition shifts the transition temperature (Caliskan et al. 2004; Cordone et al. 1999; Cornicchi et al. 2005, 2006; Paciaroni et al. 2002; Tsai et al. 2000). The term "slaving" has been used to express that the solvent imposes its dynamics on the macromolecule (Fenimore et al. 2002, 2004; Iben et al. 1989). In particular, molecular dynamics (MD) simulations have shown that the onset of translational diffusion of hydration-water triggers the protein dynamical transition in soluble proteins (Tarek and Tobias 2002; Tournier et al. 2003). In the PM, however, the onset of translational motion in hydration water occurs at $200 \mathrm{~K}$ (Berntsen et al. 2005; Weik 2003; Weik et al. 2005; Wood et al. 2007), i.e. well below the dynamical transition of membrane motions. Membrane-protein motions might be controlled by lipid motions (Kamihira and Watts 2006) rather than by water motions (Wood et al. 2007). Nevertheless, water is required to allow the conformational changes necessary for BR to function (Buchsteiner et al. 2007; Dencher et al. 2000; Weik et al. 1998).

Here, we employed incoherent elastic neutron scattering and neutron diffraction to study hydration water in stacks of deuterated PM. The first part of this study extends previous neutron-diffraction measurements that showed intermembrane heavy water $\left(\mathrm{D}_{2} \mathrm{O}\right)$ in the second hydration layers turns liquid-like at $200 \mathrm{~K}$ in flash-cooled naturalabundance PM (Weik et al. 2005). Here, the results have been reproduced for deuterated PM hydrated in light water $\left(\mathrm{H}_{2} \mathrm{O}\right)$. In the second part, atomic MSD of hydration-water and $\mathrm{PM}$ dynamics were measured separately by using deuterated $\mathrm{PM}$ in $\mathrm{H}_{2} \mathrm{O}$ and hydrogenated $\mathrm{PM}$ in $\mathrm{D}_{2} \mathrm{O}$, respectively. In complement to an earlier study on samples with high hydration (three to four water layers between successive PM patches at room temperature) (Wood et al. 2007), we here present data on the same samples, yet at a lower hydration level corresponding to only two water layers between successive membrane fragments. Again, dynamical transitions of hydration-water and of membrane motions are observed at 200 and at $260 \mathrm{~K}$, respectively, indicating that hydration-water and PM motions on the ns-ps time scale are uncoupled below $260 \mathrm{~K}$.

\section{Materials and methods}

\section{Sample preparation}

Two PM samples were prepared, a fully deuterated one (denoted D-PM) and a natural-abundance one (denoted $\mathrm{H}-$ PM). Both were purified from Halobacterium salinarum (H. salinarum) as described previously (Oesterhelt and Stoeckenius 1974). To produce fully deuterated PM, $H$. salinarum were grown on deuterated algal medium (Patzelt et al. 1997). Two hundred milligram samples of both D-PM and H-PM were used, as deduced from the BR concentration determined by the absorbance at $565 \mathrm{~nm}$ on the $\mathrm{PM}$ suspensions obtained after purification. $\mathrm{D}_{2} \mathrm{O}$ in the deuterated PM sample (denoted D-PM- $\mathrm{H}_{2} \mathrm{O}$ ) and $\mathrm{H}_{2} \mathrm{O}$ in the hydrogenated sample (denoted H-PM- $\mathrm{D}_{2} \mathrm{O}$ ) were exchanged against $\mathrm{H}_{2} \mathrm{O}$ and $\mathrm{D}_{2} \mathrm{O}$, respectively, by three successive centrifugation steps. The two concentrated membrane suspensions were then placed on $4 \times 3 \mathrm{~cm}^{2}$ flat aluminium sample holders. The sample holders were placed in dessicators over silica gel for $12 \mathrm{~h}$ to achieve partial drying to approximately $0.5 \mathrm{~g}$ water/g membrane, as determined by weighing the holder regularly until it contained approximately $300 \mathrm{mg}$ of sample. Vacuum was not applied to the dessicator at any stage of the sample preparation. The silica gel was exchanged for a saturated $\mathrm{KNO}_{3}$ solution [in $\mathrm{H}_{2} \mathrm{O}$ for the D-PM- $\mathrm{H}_{2} \mathrm{O}$ sample and in $\mathrm{D}_{2} \mathrm{O}$ for the H-PM- $\mathrm{D}_{2} \mathrm{O}$ sample, respectively; yielding a relative humidity (r.h.) of 93\%] for 7 days until the weight was stable. The D-PM- $\mathrm{H}_{2} \mathrm{O}$ sample was then equilibrated over pure $\mathrm{H}_{2} \mathrm{O}$ (100\% r.h.) for 2 days, called a "high-hydration" (Hh) level, and is hereafter denoted D-PM- $\mathrm{H}_{2} \mathrm{O}-\mathrm{Hh}$. The high-hydration level corresponds to about $0.3 \mathrm{~g}$ water $/ \mathrm{g}$ membrane. The sample holder was sealed with indium and closed with an aluminium cover, 
resulting in a sample chamber of $0.3 \mathrm{~mm}$ thickness. After temperature-dependent neutron diffraction experiments (see below), the D-PM- $\mathrm{H}_{2} \mathrm{O}-\mathrm{Hh}$ sample was opened and equilibrated for $3 \frac{1 / 2}{2}$ days over a saturated $\mathrm{KCl}$ solution (86\% r.h.; in $\mathrm{H}_{2} \mathrm{O}$ ), leading to a "low-hydration" (Lh) level of $0.1 \mathrm{~g}$ water $/ \mathrm{g}$ membrane. The sample was then sealed, closed again $(0.3 \mathrm{~mm}$ chamber thickness $)$ and denoted D-PM- $\mathrm{H}_{2} \mathrm{O}-\mathrm{Lh}$. The H-PM- $\mathrm{D}_{2} \mathrm{O}$ sample was equilibrated for 2 days over pure $\mathrm{D}_{2} \mathrm{O}(100 \%$ r.h.) and then for $3 \frac{1}{2}$ days in a $\mathrm{D}_{2} \mathrm{O}$ atmosphere at $86 \%$ r.h. (resulting in $0.1 \mathrm{~g}$ water $/ \mathrm{g}$ membrane), before it was sealed and closed $(0.3 \mathrm{~mm}$ chamber thickness): it is denoted H-PM- $\mathrm{D}_{2} \mathrm{O}-\mathrm{Lh}$. An estimate of the number of hydrogen and deuterium atoms in the different components of the H-PM- $\mathrm{D}_{2} \mathrm{O}-\mathrm{Lh}$ and D-PM- $\mathrm{H}_{2} \mathrm{O}-\mathrm{Lh}$ samples is given in Table 1.

Neutron diffraction as a function of temperature to determine lamellar spacing

As water evaporated from the membrane preparation, the PM patches oriented parallel to the surface of the sample holder, forming a stack of membranes with a characteristic repeat distance, called the lamellar spacing. The number of water layers intercalated between adjacent membrane fragments depends on the sample preparation protocol (r.h. and equilibration time) and can be determined by measuring the lamellar spacing using neutron diffraction. Lamellar spacings were determined on the diffractometer D16 at the Institut Laue-Langevin (ILL) by monitoring the first-order Bragg peak of the PM stack using a wavelength of $4.56 \AA$ (Weik et al. 2005).

The D-PM- $\mathrm{H}_{2} \mathrm{O}-\mathrm{Hh}$ sample was characterised by a lamellar spacing of $62 \AA$ at room temperature,

Table 1 Number of hydrogen atoms in the different sample components, considering $1 \mathrm{BR}$ molecule and associated lipid and water molecules for the H-PM-D ${ }_{2} \mathrm{O}-\mathrm{Lh}$ and D-PM- $\mathrm{H}_{2} \mathrm{O}-\mathrm{Lh}$ samples

\begin{tabular}{lcc}
\hline & $\begin{array}{l}\text { Number of deuterium } \\
\text { atoms }\end{array}$ & $\begin{array}{l}\text { Number of hydrogen } \\
\text { atoms }\end{array}$ \\
\hline H-PM-D 2 O-Lh & & \\
BR & 220 & 1,728 \\
Lipids & 32 & 505 \\
Water & 450 & - \\
D-PM- ${ }_{2}$ O-Lh & & \\
BR & 1,728 & 220 \\
Lipids & 505 & 32 \\
Water & - & 474 \\
\hline
\end{tabular}

The calculation has been performed assuming that all the exchangeable hydrogen atoms in the lipid head-groups, and $60 \%$ of those in the protein have exchanged (Zaccai and Gilmore 1979) corresponding to an average inter-membrane water layer of $13 \AA$ (the average thickness of a dry PM fragment is $49 \AA$ ). To determine its lamellar spacing after flash-cooling as a function of temperature upon heating (Weik et al. 2005), the sample holder was plunged into liquid nitrogen and then transferred into a cryostat pre-cooled at $100 \mathrm{~K}$. The lamellar spacing was determined at $100 \mathrm{~K}$ and then on heating from 180 to $290 \mathrm{~K}$. The time interval between successive data points was $28 \mathrm{~min}$.

Subsequently, the D-PM- $\mathrm{H}_{2} \mathrm{O}-\mathrm{Hh}$ sample was opened, re-equilibrated to a lower hydration level (Lh) (see preceding section) and re-sealed. The lamellar spacing of the D-PM- $\mathrm{H}_{2} \mathrm{O}-\mathrm{Lh}$ and the H-PM- $\mathrm{D}_{2} \mathrm{O}-\mathrm{Lh}$ samples were then measured, and the samples were opened and re-hydrated/ dehydrated as necessary until a lamellar spacing of $54 \AA$ at room temperature was reached, corresponding to a $5 \AA$ thick inter-membrane water layer. Identical lamellar spacings of the two samples ensured identical hydration levels. Between neutron scattering experiments, the samples were stored at $-20^{\circ} \mathrm{C}$.

Elastic incoherent neutron scattering (EINS) experiments

Owing to their particular wavelengths and energies, thermal and cold neutrons are an important probe for macromolecular structure and thermal dynamics (Gabel et al. 2002). The incoherent cross section of hydrogen atoms is about 40 times larger than that of deuterium, and much larger than those of all other atoms present in biological macromolecules. Using deuterium labelling, it is therefore possible to focus on different components of a complex system. In the present work, studying fully deuterated $\mathrm{PM}$ in $\mathrm{H}_{2} \mathrm{O}$ allowed us to predominantly measure hydration water dynamics. Natural-abundance PM hydrated in $\mathrm{D}_{2} \mathrm{O}$, on the other hand, provided information about membrane motions. Indeed, $60 \%$ of the total incoherent scattering cross section of D-PM- $\mathrm{H}_{2} \mathrm{O}-\mathrm{Lh}$ is due to the contribution of inter-membrane water. For H-PM- $\mathrm{D}_{2} \mathrm{O}-\mathrm{Lh}$, the contribution of the $\mathrm{D}_{2} \mathrm{O}$ is negligible, and protein (BR) and lipid make up 77 and $23 \%$, respectively. In the estimations, we consider that $60 \%$ of the exchangeable hydrogen/deuterium atoms in bacteriorhodopsin exchange, and that all of the exchangeable hydrogen/deuterium atoms in the lipid head groups do so (Zaccai and Gilmore 1979).

So-called "elastic" scans (the elastic intensity only is recorded) were performed as a function of temperature on the IN16 backscattering spectrometer at the ILL, with an energy resolution of $0.9 \mu \mathrm{eV}$ (full width at half maximum of the elastic peak) (Frick and Gonzalez 2001) and a wavelength of $6.275 \AA$. The $Q$-range accessible is $0.02-$ $1.9 \AA^{-1}$, corresponding to movements on the angstrom $(\AA)$ scale. At the given instrumental resolution, hydrogen 
movements with characteristic times faster than $1 \mathrm{~ns}$ are monitored, which reflect the dynamics of the larger groups to which they are attached. A sudden drop in the elastic signal is indicative of an increase in movements faster than $1 \mathrm{~ns}$ on the angstrom $(\AA)$ length scale.

D-PM- $\mathrm{H}_{2} \mathrm{O}-\mathrm{Lh}$ and $\mathrm{H}-\mathrm{PM}-\mathrm{D}_{2} \mathrm{O}-\mathrm{Lh}$ samples were placed in a standard "orange" cryostat at room temperature at an angle of $135^{\circ}$ with respect to the incident beam and then cooled to $50 \mathrm{~K}$ in about $2 \mathrm{~h}$. Subsequently, the elastic energy was recorded on heating from 50 to $300 \mathrm{~K}$ at constant rates of 0.16 and $0.17 \mathrm{~K} / \mathrm{min}$ for the D-PM- $\mathrm{H}_{2} \mathrm{O}-$ $\mathrm{Lh}$ and the H-PM- $\mathrm{D}_{2} \mathrm{O}-\mathrm{Lh}$ samples, respectively. The acquisition was continuous on heating and the data were subsequently binned into points corresponding to a temperature step of about $5 \mathrm{~K}$. The signal from the empty sample holder was subtracted, and the data were normalised to the intensity at $50 \mathrm{~K}$.

From the wave-vector $(Q)$ dependence of the elastic intensity $(Q=4 \pi \sin \theta / \lambda$, in which $2 \theta$ is the angle of the scattered neutron and $\lambda$ is the neutron wavelength), the mean square displacement (MSD) $\left\langle u^{2}\right\rangle$ of the investigated movements can be calculated according to the Gaussian approximation, which is valid for $Q^{2}\left\langle u^{2}\right\rangle<2$ :

$I(Q, \omega=0)=I_{0} \exp \left(-\frac{1}{6}\left\langle u^{2}\right\rangle Q^{2}\right)$

$I(Q, \omega=0)$ is the normalised elastically scattered intensity and $I_{0}$ is the value of the scattering at $Q=0$.

MSD were calculated in the $Q$-ranges $0.2<Q^{2}$ $<1.5 \AA^{-2}$ for H-PM-D ${ }_{2} \mathrm{O}$-Lh and $0.2<Q^{2}<0.9 \AA^{-2}$ for D-PM- $\mathrm{H}_{2} \mathrm{O}-\mathrm{Lh}$. At high $Q$, the range used for the deuterated PM sample is limited by a coherent peak centered at approximately $Q=1.4 \AA^{-1}$ arising from the spacing of deuterated lipids at $4.5 \AA$ (Henderson 1975), which is not constant with temperature.

The elastic intensity summed over all $Q$-values used for MSD determination, which was first used as a guide for interpreting MSD in neutron biological dynamics studies by Reat et al. (2000), is also presented as a function of temperature. Limited to the first term, the expansion of the exponential of Eq. 1 gives

$\sum_{Q_{1}}^{Q_{n}} I(Q, \omega=0) \approx I_{0}\left(1-b\left\langle u^{2}\right\rangle\right)$,

where $b$ is a constant depending only on the $Q$ values over which the sum is performed. In a first-order approximation, the summed elastic intensity is therefore proportional to the MSD $\left\langle u^{2}\right\rangle$. The quantity was normalised to unity at low temperature by dividing the sum by the number of detectors over which it was performed.

\section{Results and discussion}

Lamellar spacing of flash-cooled D-PM- $\mathrm{H}_{2} \mathrm{O}-\mathrm{Hh}$ as a function of temperature

The samples described here are formed of stacked PM fragments, intercalated by a number of water layers at room temperature that can be adjusted according to different equilibration protocols (see "Materials and methods"). If the lamellar spacing at room temperature is larger than $54 \AA$, excess inter-membrane water leaves the membrane stack upon slow-cooling at temperatures around $260 \mathrm{~K}$ until a minimal spacing of $54 \AA$ is reached and forms crystalline ice outside the stack (Lechner et al. 1998). Only two layers of water (corresponding to $54-49 \AA=5 \AA$ ) remain thus in the intermembrane space below $260 \mathrm{~K}$. Upon flash-cooling, however, $9 \AA$ of water (three to four layers) can be trapped in natural-abundance PM hydrated in $\mathrm{D}_{2} \mathrm{O}$ (Weik et al. 2005). On heating, two of the four water layers are observed to leave the stack at $200 \mathrm{~K}$ to form crystalline ice, and the lamellar spacing decreases to $54 \AA$. The decrease in lamellar spacing at $200 \mathrm{~K}$ has been attributed to an onset of translational mobility of inter-membrane water in the second hydration shells. Above $260 \mathrm{~K}$, swelling of the membrane stacks is observed as crystalline ice melts and returns in the inter-membrane space. Samples with a lamellar spacing of $54 \AA$ at room temperature do not exhibit major changes, and the spacing remains constant (to within $0.3 \AA$ ) as a function of temperature (Lechner et al. 1998). The different scenarios are schematised in Fig. 1.

The earlier studies measured $\mathrm{D}_{2} \mathrm{O}$ in natural-abundance PM (Weik et al. 2005). Here, we examined the temperature-dependent lamellar spacing of the D-PM$\mathrm{H}_{2} \mathrm{O}-\mathrm{Hh}$ sample to address possible isotope effects. Figure 2 shows the lamellar spacing of flash-cooled D$\mathrm{PM}-\mathrm{H}_{2} \mathrm{O}-\mathrm{Hh}$ upon heating, which exhibits a similar temperature dependence to the one of $\mathrm{H}-\mathrm{PM}-\mathrm{D}_{2} \mathrm{O}-\mathrm{Hh}$ measured earlier (Weik et al. 2005). The lamellar spacing of about $57.5 \AA$ remains constant up to $200 \mathrm{~K}$, then decreases to reach a minimal value of $54 \AA$ at $250 \mathrm{~K}$ (only first hydration layers remain) and increases again above $260 \mathrm{~K}$ to reach the initial value of $62 \AA$ at room temperature. The lamellar spacing of $\mathrm{H}-\mathrm{PM}-\mathrm{D}_{2} \mathrm{O}-\mathrm{Hh}$ (Weik et al. 2005) and D-PM- $\mathrm{H}_{2} \mathrm{O}-\mathrm{Hh}$ samples thus display an identical temperature-dependence within the experimental temperature error estimated to be about $5 \mathrm{~K}$. Second hydration-layer water, $\mathrm{H}_{2} \mathrm{O}$ or $\mathrm{D}_{2} \mathrm{O}$, thus turns liquid-like at $200 \mathrm{~K}$. 


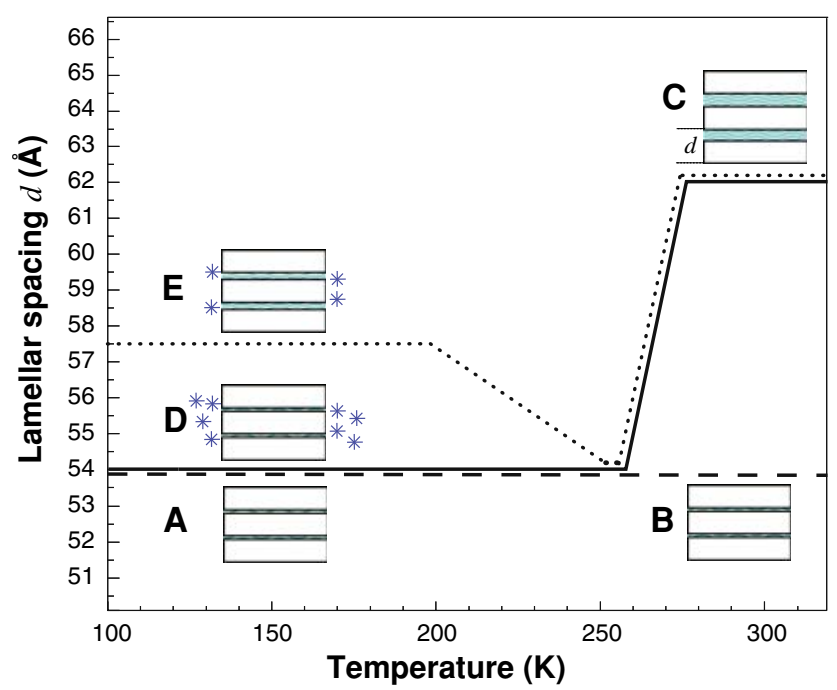

Fig. 1 Schematic representation of the lamellar spacing $d$ of a hydrated purple membrane stack as a function of temperature (after Lechner et al. 1998; Weik et al. 2005). Purple membranes are sketched as open rectangles intercalated by hydration water layers depicted as waved lines $(A-E)$. Low-hydration (Lh) samples (dashed line) have a constant lamellar spacing of $54 \AA$ in the temperature range from $100 \mathrm{~K}(A)$ to $300 \mathrm{~K}(B)$. High-hydration (Hh) samples (full and dotted lines) are characterised by a lamellar spacing of $62 \AA$ at $300 \mathrm{~K}(C)$. Upon heating the Hh sample after slow-cooling (full line; $C$ and $D$ ), the lamellar spacing increases at $260 \mathrm{~K}$. Part of the hydration water had left the inter-membrane space during slowcooling and is present as crystalline ice (depicted by stars in $D$ ) outside the membrane stacks at $100 \mathrm{~K}(D)$. Upon heating the Hh sample after flash-cooling (dotted line; $C, E$ ), water leaves the intermembrane space at $200 \mathrm{~K}$, which causes a decrease in the lamellar spacing, and forms ice. At $260 \mathrm{~K}$, the lamellar spacing increases again. A fraction of inter-membrane water had been trapped during flash-cooling, and less crystalline ice has formed in $E$ than in $D$

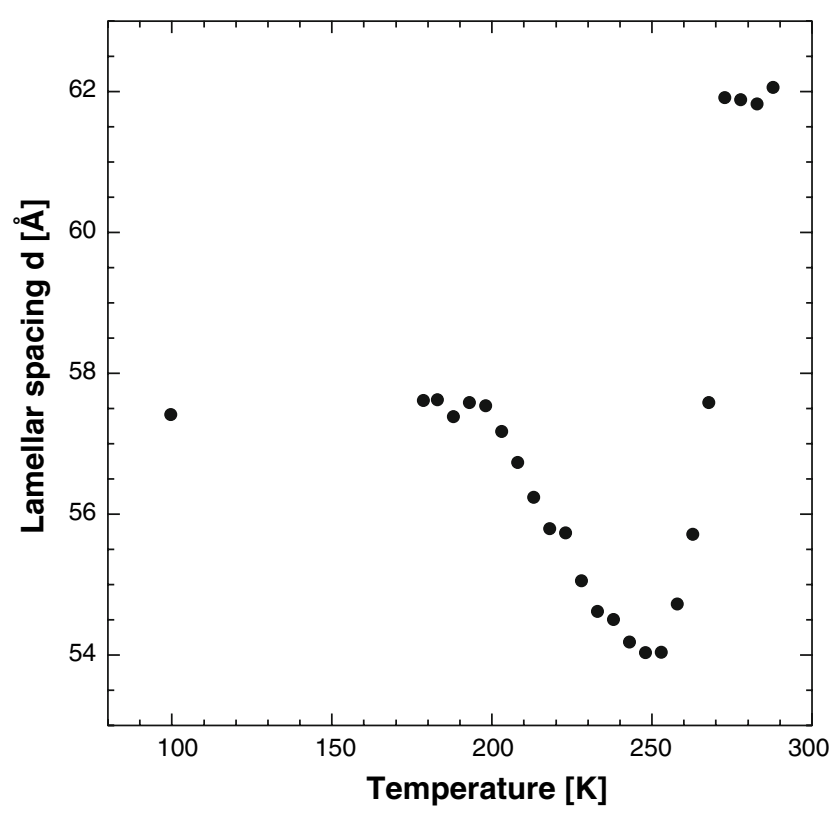

Fig. 2 Lamellar spacing of D-PM stacks, equilibrated in $\mathrm{H}_{2} \mathrm{O}$, after flash cooling in liquid nitrogen, upon heating from 100 to $290 \mathrm{~K}$
Comparison of PM dynamics (H-PM- $\mathrm{D}_{2} \mathrm{O}-\mathrm{Lh}$ sample) and dynamics of the first layer of hydration water (D-PM- $\mathrm{H}_{2} \mathrm{O}-\mathrm{Lh}$ sample)

A direct comparison of PM and hydration-water dynamics has been made recently by EINS using deuterated membranes hydrated in $\mathrm{H}_{2} \mathrm{O}$ (the same D-PM- $\mathrm{H}_{2} \mathrm{O}-\mathrm{Hh}$ sample as the one examined in the previous section) and naturalabundance membranes in $\mathrm{D}_{2} \mathrm{O}$ (Wood et al. 2007). A transition in the mean square displacements of hydration water at $200 \mathrm{~K}$, attributed by MD simulations to the onset of water translational mobility, did not trigger a dynamical transition in PM that, in fact, took place at $260 \mathrm{~K}$. The samples were characterised by a high-hydration level
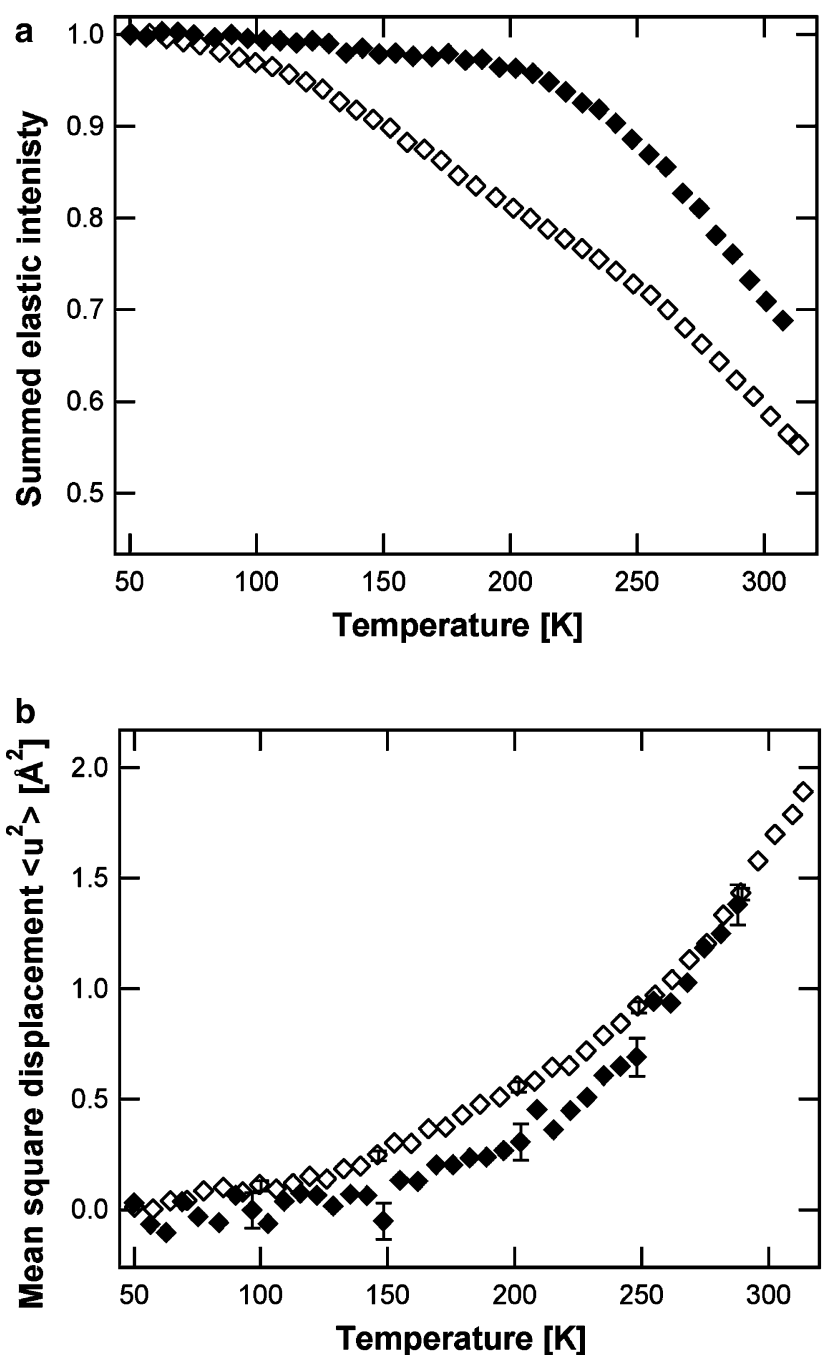

Fig. 3 Comparison of purple membrane dynamics (H-PM-D ${ }_{2} \mathrm{O}-\mathrm{Lh}$; open diamonds) and hydration water dynamics (D-PM- $\mathrm{H}_{2} \mathrm{O}-\mathrm{Lh}$; filled diamonds). a Sum of the scattered normalised elastic intensity as a function of temperature. Inflections can be seen at approximately 120 and $260 \mathrm{~K}$ in the purple membrane data and at 200 and $260 \mathrm{~K}$ in the hydration water data. $\mathbf{b}$ Mean square displacements as a function of temperature 
corresponding to a lamellar spacing of $62 \AA$ at room temperature (i.e. $13 \AA$ of inter-membrane water) that is not constant as a function of (cryo-) temperature (see Fig. 1). Here, we present data on samples with a lower hydration level corresponding to a lamellar spacing of $54 \AA$ (i.e. $5 \AA$ of inter-membrane water), which varies by less than $0.3 \AA$ between 300 and $50 \mathrm{~K}$. Furthermore, upon heating and cooling, no crystalline ice is formed (Lechner et al. 1998).

Figure 3 shows the elastic intensity summed over the $Q$ range examined (see "Materials and methods") and the extracted MSD of D-PM- $\mathrm{H}_{2} \mathrm{O}-\mathrm{Lh}$ and HPM- $\mathrm{H}_{2} \mathrm{O}-\mathrm{Lh}$. The elastic intensities (Fig. 3a) are very different for both samples, with inflections seen at approximately the same temperatures for which they were seen in the "highhydration" samples (Wood et al. 2007): 120 and $260 \mathrm{~K}$ for the H-PM- $\mathrm{D}_{2} \mathrm{O}-\mathrm{Lh}$ sample, 200 and $260 \mathrm{~K}$ for the D-PM$\mathrm{H}_{2} \mathrm{O}-\mathrm{Lh}$ sample.

Using the summed elastic intensities (where the error on each point is of the size of the points in Fig. 3a) as a guide, the atomic MSD of water and PM motions can be divided into regions with different characteristic temperatures. Below $120 \mathrm{~K}$, MSD of both membrane (H-PM- ${ }_{2} \mathrm{O}-\mathrm{Lh}$ sample) and water (D-PM- $\mathrm{H}_{2} \mathrm{O}-\mathrm{Lh}$ ) are similar. Following an inflection at $120 \mathrm{~K}$, the membrane's MSD are clearly above the water's MSD up to $260 \mathrm{~K}$-the membrane has larger amplitude motions than its hydration water. The hydration water MSD evolves linearly with temperature to a higher temperature than PM, and undergo a broad transition at $200 \mathrm{~K}$. At $260 \mathrm{~K}$, the water MSD catches up with the membrane MSD and are almost identical to them up until $288 \mathrm{~K}$. Above $288 \mathrm{~K}$, it becomes impossible to calculate MSD for the water molecules, since their motions become too large to be resolved, and the Gaussian approximation is no longer valid.

Although the same transition temperatures are observed for the low-hydration samples studied here and the highhydration samples measured earlier (Wood et al. 2007), small differences in the dynamics of water in the two hydration states can be seen. Water MSDs for the highhydration and low-hydration samples are plotted for comparison in Fig. 4, where two temperature regions with significant differences in dynamics are evident. The first is between 150 and approximately $200 \mathrm{~K}$, where the lowhydration sample displays larger MSD than the highhydration sample. This indicates that the two inter-membrane water layers, present in both high- and low-hydration samples, are more mobile than ice in the same temperature region. The second temperature region where a large difference is observed is above $260 \mathrm{~K}$, temperature above which in the case of high-hydration samples the ice present in the sample melts and flows back into the membrane stack and $13 \AA$ of water is in the inter-lamellar space. Above $260 \mathrm{~K}$, water in the high-hydration sample has

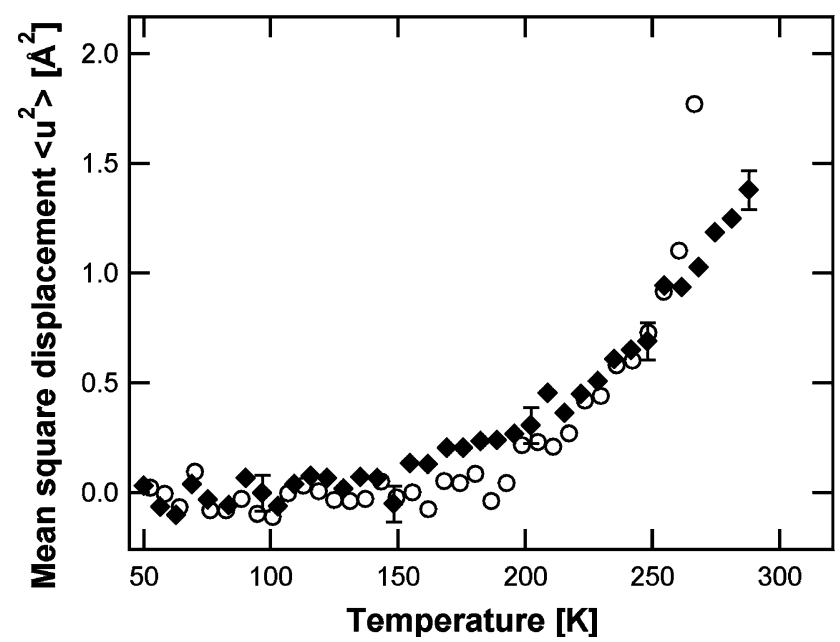

Fig. 4 Comparison of water dynamics in high-hydration (Wood et al. 2007) and low-hydration samples (from Fig. 3b). Atomic mean square displacements of D-PM- $\mathrm{H}_{2} \mathrm{O}-\mathrm{Lh}$ (filled diamonds) and D-PM$\mathrm{H}_{2} \mathrm{O}-\mathrm{Hh}$ (open circles) are shown as a function of temperature. For the low-hydration sample, all of the water is inter-membrane in the whole temperature region and contributes to $60 \%$ of the scattering cross section ( $40 \%$ is due to PM atoms). For the high-hydration samples, below $250 \mathrm{~K}$, the water is in two forms: inter-membrane water and ice, which contribute, respectively, 31 and $49 \%$ to the scattering. Above $270 \mathrm{~K}, 80 \%$ of the scattering comes from intermembrane water in the high-hydration sample $(20 \%$ is due to PM atoms). In this estimation, it is assumed that all the exchangeable protons/deuterons in the lipid head-groups exchange and that $60 \%$ of those in the protein do so

much larger MSD than water in the low-hydration sample, implying that four layers of water confined in PM stacks show on average higher mobility on the ps-ns time scale than two water layers.

The main conclusion by Wood et al. (2007) is confirmed by the present experiments at a lower hydration level: the dynamical transition in the hydration water at $200 \mathrm{~K}$ does not trigger a transition in the membrane at the same temperature. Since BR contributes most to the scattering cross section of PM, it can be supposed that the absence of a transition at $200 \mathrm{~K}$ in the whole PM indicates that no transition occurs in the protein. The result suggests that, in contrast to soluble proteins, the dynamics of water and membrane proteins on the ns-ps time scale are decoupled below $260 \mathrm{~K}$, possibly suggesting an important role of lipids in the dynamical interdependency of BR, lipids and water.

Acknowledgments We are grateful to Heloisa Nunes Bordallo, Bruno Demé and Bernhard Frick for their help during data collection at the ILL. We also thank Marek Koza and Douglas Tobias for fruitful discussions. Financial support by the CEA, the CNRS and the UJF is acknowledged, as well as a grant to MW from the Agence Nationale de la Recherche (project number JC05_45685). The study was supported by the EU DLAB program under contract numbers HPRI-CT-2001-50035 and RII3-CT-2003-505925. 


\section{References}

Berntsen P, Bergman R, Jansson H, Weik M, Swenson J (2005) Dielectric and calorimetric studies of hydrated purple membrane. Biophys J 89:3120-3128

Buchsteiner A, Lechner RE, Hauss T, Dencher NA (2007) Relationship between structure, dynamics and function of hydrated purple membrane investigated by neutron scattering and dielectric spectroscopy. J Mol Biol 371:914-923

Caliskan G, Briber RM, Thirumalai D, Garcia-Sakai V, Woodson SA, Sokolov AP (2006) Dynamic transition in tRNA is solvent induced. J Am Chem Soc 128:32-33

Caliskan G, Mechtani D, Roh JH, Kisliuk A, Sokolov AP, Azzam S, Cicerone MT, Lin-Gibson S, Peral I (2004) Protein and solvent dynamics: how strongly are they coupled? J Chem Phys 121:1978-1983

Cordone L, Ferrand M, Vitrano E, Zaccai G (1999) Harmonic behavior of trehalose-coated carbon-monoxy-myoglobin at high temperature. Biophys J 76:1043-1047

Cornicchi E, Marconi M, Onori G, Paciaroni A (2006) Controlling the protein dynamical transition with sugar-based bioprotectant matrices: a neutron scattering study. Biophys J 91:289-297

Cornicchi E, Onori G, Paciaroni A (2005) Picosecond-time-scale fluctuations of proteins in glassy matrices: the role of viscosity. Phys Rev Lett 95:158104

Dencher NA, Sass HJ, Buldt G (2000) Water and bacteriorhodopsin: structure, dynamics, and function. Biochim Biophys Acta 1460:192-203

Doster W, Cusack S, Petry W (1989) Dynamical transition of myoglobin revealed by inelastic neutron scattering. Nature 337:754-756

Engelman DM, Zaccai G (1980) Bacteriorhodopsin is an inside-out protein. Proc Natl Acad Sci USA 77:5894-5898

Fenimore PW, Frauenfelder H, McMahon BH, Parak FG (2002) Slaving: solvent fluctuations dominate protein dynamics and functions. Proc Natl Acad Sci USA 99:16047-16051

Fenimore PW, Frauenfelder H, McMahon BH, Young RD (2004) Bulk-solvent and hydration-shell fluctuations, similar to alphaand beta-fluctuations in glasses, control protein motions and functions. Proc Natl Acad Sci USA 101:14408-14413

Ferrand M, Dianoux AJ, Petry W, Zaccai G (1993) Thermal motions and function of bacteriorhodopsin in purple membranes: effects of temperature and hydration studied by neutron scattering. Proc Natl Acad Sci USA 90:9668-9672

Fitter J (1999) The temperature dependence of internal molecular motions in hydrated and dry alpha-amylase: the role of hydration water in the dynamical transition of proteins. Biophys $\mathrm{J}$ 76:1034-1042

Fitter J, Lechner RE, Buldt G, Dencher NA (1996) Internal molecular motions of bacteriorhodopsin: hydration-induced flexibility studied by quasielastic incoherent neutron scattering using oriented purple membranes. Proc Natl Acad Sci USA 93:7600-7605

Fitter J, Lechner RE, Dencher NA (1997) Picosecond molecular motions in bacteriorhodopsin from neutron scattering. Biophys $\mathbf{J}$ 73:2126-2137

Fitter J, Verclas SA, Lechner RE, Seelert H, Dencher NA (1998) Function and picosecond dynamics of bacteriorhodopsin in purple membrane at different lipidation and hydration. FEBS Lett 433:321-325

Frick B, Gonzalez M (2001) Five years operation of the second generation backscattering spectrometer IN16-a retrospective, recent developments and plans. Phys B Condens Matter 301:819
Gabel F, Bicout D, Lehnert U, Tehei M, Weik M, Zaccai G (2002) Protein dynamics studied by neutron scattering. Q Rev Biophys 35:327-367

Henderson R (1975) The structure of the purple membrane from Halobacterium hallobium: analysis of the X-ray diffraction pattern. J Mol Biol 93:123-138

Iben IE, Braunstein D, Doster W, Frauenfelder H, Hong MK, Johnson JB, Luck S, Ormos P, Schulte A, Steinbach PJ, Xie AH, Young RD (1989) Glassy behavior of a protein. Phys Rev Lett 62:19161919

Kamihira M, Watts A (2006) Functionally relevant coupled dynamic profile of bacteriorhodopsin and lipids in purple membranes. Biochemistry 45:4304-4313

Lechner RE, Fitter J, Dencher NA, Hauss T (1998) Dehydration of biological membranes by cooling: an investigation on the purple membrane. J Mol Biol 277:593-603

Lehnert U, Reat V, Weik M, Zaccai G, Pfister C (1998) Thermal motions in bacteriorhodopsin at different hydration levels studied by neutron scattering: correlation with kinetics and light-induced conformational changes. Biophys J 75:1945-1952

Oesterhelt D, Stoeckenius W (1974) Isolation of the cell membrane of Halobacterium halobium and its fractionation into red and purple membrane. Methods Enzymol 31:667-678

Paciaroni A, Cinelli S, Onori G (2002) Effect of the environment on the protein dynamical transition: a neutron scattering study. Biophys J 83:1157-1164

Patzelt H, Ulrich AS, Egbringhoff H, Düx P, Ashurst J, Simon B, Oschkinat H, Oesterhelt D (1997) Structural investigation on isotope labelled native bacteriorhodopsin in detergent micelles by NMR spectroscopy. J Biomol NMR 10:95-106

Pieper J, Hauss T, Buchsteiner A, Baczynski K, Adamiak K, Lechner RE, Renger G (2007) Temperature- and hydrationdependent protein dynamics in photosystem II of green plants studied by quasielastic neutron scattering. Biochemistry 46:11398-11409

Reat V, Dunn R, Ferrand M, Finney JL, Daniel RM, Smith JC (2000) Solvent dependence of dynamic transitions in protein solutions. Proc Natl Acad Sci USA 97:9961-9966

Reat V, Patzelt H, Ferrand M, Pfister C, Oesterhelt D, Zaccai G (1998) Dynamics of different functional parts of bacteriorhodopsin: $\mathrm{H}-2 \mathrm{H}$ labeling and neutron scattering. Proc Natl Acad Sci USA 95:4970-4975

Roh JH, Curtis JE, Azzam S, Novikov VN, Peral I, Chowdhuri Z, Gregory RB, Sokolov AP (2006) Influence of hydration on the dynamics of lysozyme. Biophys J 91:2573-2588

Tarek M, Tobias DJ (2002) Role of protein-water hydrogen bond dynamics in the protein dynamical transition. Phys Rev Lett 88:138101

Tournier AL, Xu J, Smith JC (2003) Translational hydration water dynamics drives the protein glass transition. Biophys $\mathrm{J}$ 85:18711875

Tsai AM, Neumann DA, Bell LN (2000) Molecular dynamics of solid-state lysozyme as affected by glycerol and water: a neutron scattering study. Biophys J 79:2728-2732

Weik M (2003) Low-temperature behavior of water confined by biological macromolecules and its relation to protein dynamics. Eur Phys J E Soft Matter 12:153-158

Weik M, Lehnert U, Zaccai G (2005) Liquid-like water confined in stacks of biological membranes at $200 \mathrm{k}$ and its relation to protein dynamics. Biophys J 89:3639-3646

Weik M, Zaccai G, Dencher NA, Oesterhelt D, Hauss T (1998) Structure and hydration of the M-state of the bacteriorhodopsin mutant D96N studied by neutron diffraction. J Mol Biol 275:625-634 
Wood K, Caronna C, Fouquet P, Hauessler W, Natali F, Ollivier J, Orecchini A, Plazanet M, Zaccai G (2008) A benchmark for protein dynamics: ribonuclease A measured by neutron scattering in a large wavevector-energy transfer range. Chem Phys. doi: 10.1016/j.chemphys.2007.09.012

Wood K, Plazanet M, Gabel F, Kessler B, Oesterhelt D, Tobias DJ, Zaccai G, Weik M (2007) Coupling of protein and hydration- water dynamics in biological membranes. Proc Natl Acad Sci USA 104:18049-18054

Zaccai G, Gilmore DJ (1979) Areas of hydration in the purple membrane of Halobacterium halobium: a neutron diffraction study. J Mol Biol 132:181-191 